\title{
Enzymatic and toxigenic ability of opportunistic fungi contaminating intensive care units and operation rooms at Assiut University Hospitals, Egypt
}

\author{
Mohamed Bassam Aboul-Nasr ${ }^{1 *}$, Abdel-Naser Ahmed Zohri ${ }^{2}$ and Enas Mahmoud Amer $^{2}$
}

\begin{abstract}
Total of 110 isolates belonging to 8 fungal species collected from intensive care units (ICUs) and operation rooms (ORs) at Assiut University hospitals were examined for their ability to produce some extracellular enzymes and mycotoxins which are considered as important factors involved in for fungal pathogenicity. The results revealed that 73, 92 and 78 out of the 110 tested isolates produced protease, lipase and urease respectively; meanwhile, 77 of the tested isolates exhibited some hemolytic activities. Chromatographic analysis (TLC) of the crude extract of the fungal isolates tested revealed that 79 isolates of them had the ability to produce at least one of these mycotoxic compounds (aflatoxins $B_{1}, B_{2}, G_{1}$, gliotoxin, fumigillin, $T-2$, zearalenone, roridin $A$ \& $E$, verrucarin $A$ \& J, trichoveroids, satratoxin $\mathrm{H} \& \mathrm{E}$ ). These results demonstrate that the opportunistic fungal species isolated from (ICUs) and (ORs) and tested exhibited some enzymatic and mycotoxic ability which are the most effective virulence factors contributing to fungal pathogenicity indicating that the management of infection control unit at Assiut University hospitals must be aware of not only bacterial but also fungal contamination.
\end{abstract}

Keywords: Airborne fungi; Enzymes; Mycotoxins and pathogenicity

\section{Introduction}

Members belonging to the Aspergillus, Fusarium and Mucorales genera are regarded as the main cause of fungal infections at hospitals (Alberti et al., 2001; Faure et al., 2000; Perdelli et al., 2006). Indeed fungi contaminating hospital rooms may grow on organic matter including various building materials and develop microcolonies. Prior to possible dissemination spores emanating from these colonies could be inhaled by immuno-suppressed patients resulting in local infections (Singh \& Paterson, 2005). The ability of fungi to cause human diseases (mycoses) as pathogens appears to be accidental and such diseases are primarily related to the immunological status of the host and environmental exposure, rather than to the infecting organism (Rippon, 1988; Kwon-Chung \& Bennett, 1992; Ellis, 1994). A relationship between fungal contamination in hospital environments and the incidence

\footnotetext{
* Correspondence: mbassamaboulnasr@yahoo.com

'Faculty of Science, Department of Botany, University of Sohag, Sohag, Egypt Full list of author information is available at the end of the article
}

of invasive aspergillosis has been demonstrated (Alberti et al., 2001) and more than 500 cases of post-operative aspergillosis in immuno-competent individuals have been reported (Pasqualotto and Denning, 2006). Aspergillus fumigatus and A. flavus are the leading species of the genus Aspergillus causing invasive aspergillosis (Pasqualotto, 2008). Outbreaks of nosocomial aspergillosis are attributed to airborne sources and even small concentrations of spores have been associated with outbreaks (Vonberg and Gastmeier, 2006).

Fungi are known to elaborate extracellular enzymes based on the substrate they utilize for growth. Extracellularly produced enzymes have been described in certain fungi such as Candida (Borg \& Ruchel, 1988) and Aspergillus species (Hanzi et al., 1993). Production and secretion of hydrolytic enzymes, such as proteases, lipases and phospholipases are very important virulence factors. These enzymes play a role in nutrition, tissue damage, fungal dissemination within the human body, iron acquisition and overcoming the host immune system 
which strongly affects fungal pathogenicity (Ibrahim et al., 1995). Secretion of enzymes into extracellular environments might be an important adaptive mechanism during the life cycle of fungi (Monod et al., 2002). Earlier studies on fungal enzymatic activities aimed at establishing the role of enzymes in fungal pathogenicity, as well as their capacity to induce inflammatory reactions in the host (Rippon, 1982). It is logical to suppose that these enzymes could act by enabling tissue invasion easier, but they could also participate in causing infection by impairing some mechanisms of the immune system and/or assist in obtaining of nutrients, thus causing injury to the host (Birch et al., 2004; Da Silva et al., 2005). Hussein and Brasel et al., (2001) examined the ability of 80 fungal isolates from keratitis patients to produce extracellular enzymes in growth medium and found that most of these isolates could produce protease, lipase, urease and catalase enzymes but at varying levels.

Mycotoxins are an extremely adverse group of low molecular weight fungal secondary metabolites which when ingested, inhaled or absorbed through the skin; can cause lowered performance, sickness or even death in man and animals including birds (Pitt, 1996 and Van Egmond \& Speijers, 1999). They may affect the reproductive, immune, gastrointestinal systems, specific target organs, in addition they may exhibit hormonal activity, developmental defects including those relating to birth (tetragenic and neurotoxic) (Richard, 1991; Sharma, 1993; Kuiper-Goodman, 2004). Although fungal spores may have the highest concentrations of mycotoxins, the vegetative part of the fungus, the mycelium or the substrate upon which the fungus grows can also contain these toxins. Viability of spores is not essential to toxicity. In other words, a dead spore can still be a source of toxin (Keller, et al., 2005). Infants and children are considered more susceptible to different toxins than adults, because of their lower body weight, higher metabolic rate, incomplete development of some organs and tissues such as those in the central nervous system (WHO, 1986; NAS, 1993). Nonetheless, human illnesses caused by mycotoxins may be a public health problem than one realizes because some of these cases (chronic) may go un-noticed for an extended period of time unless large amounts of mycotoxins are consumed resulting in acute symptomology (Hesseltine, 1985). Like the case may be for other hospital infection control units elsewhere, Assiut University hospitals only focus on bacterial infection. This study was directed to examine the potential of the most common fungal species isolated from the atmospheric air and dust samples collected from air conditioners of ICUs and ORs to produce extracellular hydrolytic enzymes and mycotoxic compounds which are important virulence factors involved in fungal pathogenicity.

\section{Materials and methods}

\section{Screening of fungal isolates for extracellular enzyme} production

A total of 110 filamentous fungi isolated from air as well as filters of air conditioning systems in intensive care units and operation rooms (noted in our laboratory) were screened for their ability to produce extracellular enzymes in solid media. The following fungal species were tested: i.e. Aspergillus flavus (20 isolates), A. fumigatus (16), A. niger (19), Cladosporium cladosporioides ( 5 ), Fusarium solani (17), F. oxysporum (6), Myrothecium roridum (1) and Stachybotrys elegans (26).

Protease activity was determined using a Casein hydrolysis medium in which skim milk gives an opaque final appearance and hydrolysis of the casein resulted in a clear zone around the fungal colony. (Paterson \& Bridge, 1994). Lipase activity was measured using the method of Ullman \& Blasins (1974) with some modification this time using Tween 80 instead of Tween 20. The lipolytic producing ability was observed as a visible precipitate due to the formation of crystals of calcium salt of the oleic acid liberated by the enzyme. Urease activity was determined using urease medium described by Paterson \& Bridge (1994). Isolates capable of producing urease turned the yellow color of the acidic medium to purple-red or deep pink color., meanwhile hemolytic activity of fungal isolates was measured using human blood agar medium (Ronald, 2000).

\section{Screening of fungal isolates for mycotoxin production Cultivation of fungal isolates and extraction of their mycotoxins}

One-hundred and ten isolates were cultivated in a $15 \mathrm{~cm}$ Petri dish containing solid Czapek's glucose agar under aseptic conditions and incubated at $25 \pm 2^{\circ} \mathrm{C}$ for 10 days. The plates containing Fusarium, Stachybotrys and Myrothecium isolates were transferred into a refrigerator for another 10 days. At the end of incubation periods, an agar plug technique was employed for the extraction of mycotoxins in culture materials, whereby, all the agar medium with fungal mycelia were cut into small pieces, transferred into a $250 \mathrm{ml}$ Erlenmeyer flask containing $50 \mathrm{ml} \mathrm{96 \%} \mathrm{methanol.} \mathrm{The} \mathrm{content} \mathrm{was} \mathrm{shaken} \mathrm{on} \mathrm{a} \mathrm{ro-}$ tary shaker (200 r.p.m., 24 h) and filtered through filter paper (Aboul-Nasr; Obied-Allah, 2013).

The extracted material was then washed using $25 \mathrm{ml}$ of the same extractin solvent. The methanol extracts were combined, dried over anhydrous sodium sulphate, and concentrated under a vacuum. The residue was transferred to a dram vial and further evaporated to near dryness.

\section{Thin layer chromatographic analysis}

For the screening of mycotoxins in extracts, a thinlayer chromatographic technique adopted by El- kady and Moubasher (1982) was employed. 


\section{Results and discussion}

The ability of clinical fungal strains from various ICUs and ORs at Assiut University hospital units were tested for their ability to produce extracellular enzymes in solid media and data presented in Table 1. Data indicated that more than $66 \%$ of tested isolates (73 out of 110) of five fungal genera; 3 Aspergillus spp. (55 isolates), one Cladosporium sp. (5 isolates), 2 Fusarium spp. (23 isolates), one Stachybotrys sp. (26 isolates) and one isolate of Myrothecium sp. had the ability to produce protease. Nearly similar percent $(70.9 \%)$ of the tested fungal isolates (78 out of 110) were recorded as lipase producers in this study. Salyers and Witt (1994) reported that microbial cells secrete hydrolytic enzymes that destroy the constituents of host cell membranes leading to membrane dysfunction, physical disruption as well as aid in the invasion of host tissues. Proteolytic degradation of lung tissues has been suggested as one of the key events involved in the physiopathology of A. fumigatus (Kothary et al., 1984). Also, several species of Aspergillus such as $A$. fumigatus, $A$. flavus, $A$. oryzae and $A$. sojae are known to secrete protease as reported by Monod et al., (1993). Stehr et al., (2003) found that extracellular lipases play a role during microbial infections and suggested their role is to digest lipids for nutrient acquisition by pathogenic microbe and that these enzymes help the microbe (bacteria or fungi) to grow in environments where lipids are the sole carbon source.

A majority of the fungal isolates under study (92 out of $110: 83.6 \%$ ) were able to produce urease. Urease catalyses the hydrolysis of urea to ammonia and carbamate, in which the latter by-product is further hydrolyzed to ammonia and carbonic acid resulting in an increase in $\mathrm{pH}$ (Zimmer, 2000). Urease activity has been found in several bacteria and fungi and has been shown to be an important pathogenic factor (Eaton et al., 1991; Cox et al., 2000). It has also been postulated that much of the tissue damage induced by Helicobacter pylori is as a result of ammonium hydroxide produced through the actions of urease. Studies have shown that the actions of urease may alter the function of white blood cells (Mai et al., 1992; Mobley, 1996). In this study, about $70.9 \%$ of the tested fungal isolates (78 out of 110) exhibited a lysis activity (heamolysis) on human blood. Vesper et al. (1999; 2001) isolated stachylysin a hemolytic agent from Stachybotrys chartarum. Donohue et al., (2004) isolated chrysolysin another hemolytic agent from $P$. chrysogenum.

The toxigenic potentials of these fungal isolates previously tested herein for their enzymatic activity were also evaluated and the data presented in Table 2 revealed that 79 out of the 110 tested fungal isolates (71.82\%) were recorded as mycotoxin producers. Several mycotoxins including aflatoxins, gliotoxin, fumigillin, cladosporin, T2 toxin, zearalenone, roridins, verrucarins, trichoveroides and satratoxins were produced by different fungal isolates in this study. Aflatoxins $\mathrm{B}_{1} \& \mathrm{~B}_{2}$ were recorded in extracts obtained from cultures of $11 \mathrm{~A}$. flavus with one positive isolates being able to produce additionally aflatoxins $\mathrm{G}_{1} \& \mathrm{G}_{2}$. Aflatoxins are produced by many strains of $A$. flavus. They are toxic, having carcinogenic, mutagenic and teratogenic effects in laboratory animals (Abdel-Wahhab et al., 1998, 2006). Aflatoxin $B_{1}$ is the most potent carcinogenic substance naturally produced mainly by $A$. flavus and A. parasiticus (Squire, 1981) and is classified by the International Agency of Research on Cancer as a group 1 human carcinogen (IARC, 1982). Gliotoxin and fumigillin were produced by all the 16 tested isolates of A. fumigatus. Also, 7 out of 19 tested isolates of $A$. niger had the ability to produce gliotoxin. Aspergillus members especially A. fumigatus and A. niger are the most common causal agents of aspergillosis. Invasive aspergillosis is very common among immunocompromised patients, with reported incidence rates of $17-26 \%$ among lung transplants patients, 5-15\% allogenic

Table 1 Extracellular enzymes produced by the tested fungal isolates collected from ICUs and ORs at Assiut University hospitals

\begin{tabular}{|c|c|c|c|c|c|c|c|c|c|}
\hline \multirow[t]{2}{*}{ Fungal isolates } & \multirow{2}{*}{$\begin{array}{l}\text { No. of tested } \\
\text { isolates }\end{array}$} & \multicolumn{2}{|c|}{ Protease } & \multicolumn{2}{|c|}{ Lipase } & \multicolumn{2}{|c|}{ Urease } & \multicolumn{2}{|c|}{ Hemolysis } \\
\hline & & $+\mathrm{Ve}$ & $-V e$ & $+\mathrm{Ve}$ & $-\mathrm{Ve}$ & $+\mathrm{Ve}$ & $-\mathrm{Ve}$ & $+\mathrm{Ve}$ & $-\mathrm{Ve}$ \\
\hline Aspergillus flavus & 20 & 16 & 4 & 19 & 1 & 20 & 0 & 19 & 1 \\
\hline Aspergillus fumigatus & 16 & 10 & 6 & 15 & 1 & 15 & 1 & 12 & 4 \\
\hline Aspergillus niger & 19 & 15 & 4 & 16 & 3 & 8 & 11 & 13 & 6 \\
\hline Cladosporium cladosporioides & 5 & 1 & 4 & 4 & 1 & 0 & 5 & 2 & 3 \\
\hline Fusarium solani & 17 & 11 & 6 & 9 & 8 & 10 & 7 & 7 & 10 \\
\hline Fusarium oxysporum & 6 & 3 & 3 & 5 & 1 & 5 & 1 & 4 & 2 \\
\hline Myrothecium roridum & 1 & 1 & 0 & 1 & 0 & 1 & 0 & 1 & 0 \\
\hline Stachybotrys elegans & 26 & 22 & 4 & 25 & 1 & 19 & 7 & 19 & 7 \\
\hline Total & 110 & 79 & 31 & 94 & 16 & 78 & 32 & 77 & 33 \\
\hline
\end{tabular}


Table 2 Mycotoxigenicity of fungal isolates collected from ICUs and ORs at Assiut University hospital

\begin{tabular}{lccc}
\hline Toxins produced & No. of strains positive & No. of strains tested & Fungal isolates \\
\hline Aflatoxins B1, B2 & 10 & 20 & Aspergillus flavus \\
Aflatoxins B1, B2, G1, G2 & 1 & 16 & Aspergillus fumigatus \\
Gliotoxin, fumigillin & 16 & 19 & Aspergillus niger \\
Gliotoxin & 7 & 5 & Cladosporium cladosporioides \\
Cladosporin & 5 & 17 & Fusarium solani \\
T-2 toxin & 9 & & Fusarium oxysporum \\
T-2 toxin, Zearalenone & 2 & 6 & Myrothecium roridum \\
Zearalenone, & 1 & 1 & Stachybotrys elegans \\
Zearalenone & 6 & 26 & \\
Roridin A \& E, Verrucarin A \& J & 1 & & \\
Trichoveroides & 10 & & \\
Trichoveroides \& verrucarin J & 6 & 5 &
\end{tabular}

bone marrow transplants patients, 5-24\% of those with acute leukaemia and $2-13 \%$ heart transplants patients (Curtis et al., 2004). Kupfahl et al., (2008) investigated the presence of gliotoxin-producing Aspergillus strains among clinical isolates collected from different parts of Germany and Austria. In that light, we collected and examined 158 different Aspergillus isolates consisting of 100 A. fumigatus, 27 A. terrus, 15 A. flavus and 16 A. niger strains from different medical centers and other environmental samples. According to that study, gliotoxin was recovered from 98, 56, 37 and 13\% of A. fumigatus, $A$. niger, A. terreus and A. flavus, respectively. Nielsen (2003) found that $A$. fumigatus and $A$. niger are frequently isolated as indoor moulds, with the former isolate having the ability to produce fumitoxins, fumitremergens, gliotoxin and other mycotoxins, while the later produced only ochratoxin A. Cladosporin was produced by five tested isolates of C. cladospoioides in this study. This species is one of the causative agents of skin lesions, keratitis, nail fungus and pulmonary infections. Also, acute symptoms of exposure to this fungus are edema and bronchiospasr which may lead to pulmonary amphysema. Zearalenone was produced by all six tested isolates of $F$. oxysporum and three out of 17 isolates of F. solani. This toxin has an estrogenic activity and this estrogenic property enables exposure to its products a concern for human health (Niyo et al., 1988, Richard, 1991). In humans, the major effect of zearalenone bears on the reproductive system affecting reproductive organs' structure and function that may lead to hyperestrogenism (Kuiper-Goodman et al., 1993). T-2 toxin productivity by 11 of the 17 tested $F$. solani isolate was recorded in this study. This toxin is a representative of a large group of non-macrocyclic trichothecenes whose major effect and that of other trichothecenes is their ability to inhibit protein synthesis which is followed by a secondary disruption of DNA and RNA synthesis (Niyo et al., 1988; Richard, 1991). Verrucarin A \& J as well as roridin A \& E are mycotoxins produced by as $M$. roridium found in this study. Also, verrucarin J was produced by 11 out of 26 tested isolates of S. elegans with 5 of this species found to produce satratoxins $\mathrm{H}$ \& E. Meanwhile 19 of the same species were able to synthesize trichoveroides. Verrucarins, roridins, trichoveroides and satratoxins. Different types of macrocyclic trichothecenes produced mainly by Stachybotrys (Eppley, 1977; Eppley and Bailey, 1973; Eppley et al., 1980). The involvement of macrocyclic trichothecenes in stachybotryotoxicosis were suggested by isolation of satratoxins from straws fed to sheep and cattle with stachybotryotoxicosis (Harrach and Bata, 1983; Harrach et al., 1983). Bata et al. (1985) found that all 17 strains of Stachybotrys atra isolated in Middle Europe and found to produce each of the five macrocyclic trichothecenes that included satratoxins $\mathrm{H} \& \mathrm{G}$, verrucarin $\mathrm{A}, \mathrm{E} \& \mathrm{~J}$, trichoveroides and roridin A \& E. Islam et al., (2006) suggested that neurotoxicity and inflammation in the nose and brain are potential adverse health effects of exposure to satratoxins.

\section{Conclusion}

In conclusion, hydrolytic enzymes and mycotoxic compounds which are considered the most important virulence factors influencing the pathogenicity of opportunistic fungal infections were detected in most of the cultures of fungal isolates tested herein. Thus the personnel managing the infection control unit of Assiut University hospitals must be aware of not only bacterial contamination, but there is a potential for the distribution of fungal infection as well. 


\section{Competing interests}

The authors declare that they have no competing interests.

\section{Authors' contributions}

MBA designed the research plan, followed the research plan execution point by point, helped in drafting the manuscript, revised it and was the corresponding author. AAZ helped in identifying the toxic profile and planed the enzyme profile experiments. EMA carried out the research plane point by point, identifying fungi and toxins under the supervision of MBA and helped in drafting the manuscript. All authors read and approved the final manuscript.

\section{Author details}

${ }^{1}$ Faculty of Science, Department of Botany, University of Sohag, Sohag, Egypt. ${ }^{2}$ Faculty of Science, Department of Botany, University of Assiut, Assiut, Egypt.

Received: 16 April 2013 Accepted: 26 July 2013

Published: 29 July 2013

\section{References}

Abdel-Wahhab MA, Nada SA, Farag IM, Abbas NF, Amra HA (1998) Potential protective effect of HSCAS and bentonite against dietary aflatoxicosis in rat: with special reference to chromosomal aberrations. Nat J Toxins 6:211-218

Abdel-Wahhab MA, Ahmed HH, Hagazi MM (2006) Prevention of aflatoxin $\mathrm{B}_{1}$-initiated hepatotoxicity in rat by marine algae extracts. J Appl Toxicol 26:229-238

Aboul-Nasr MB, Obied-Allah MR (2013) Biological and Chemical Detection of Fumonisins Produced on Agar Medium by Fusarium verticillioides Isolates Collected from Corn in Sohag-Egypt. J Microbiol, Epub ahead of print

Alberti C, Bouakline A, Ribaud P, Lacroix C, Rousselot P, Leblanc T (2001) Relationship between environmental fungal contamination and the incidence of invasive aspergillosis in haematology patients. J Hosp Infect 48:198-206

Bata A, Balazs H, Ujszaszi K, Kis-Tamas A, Lasztity R (1985) Macrocyclic trichothecene toxins produced by Stachybotrys atra strains isolated in Middle Europe. J Appl \& Environ Microbiol 49(3):678-681

Birch M, Denning DW, Robson GD (2004) Comparison of extracellular phospholipase activities in clinical and environmental Aspergillus fumigatus isolates. J Med Mycol 42:81-86

Borg M, Ruchel R (1988) Expression of extracellular acid proteinase by proteolytic Candida species during experimental infection of oral mucosa. J Infect Immun 56:626-663

Cox GM, Mukherjee J, Cole GT, Casadevall A, Perfect JR (2000) Urease as a virulence factor in experimental cryptococcosis. J Infect Immun 68:443-448

Curtis MS, Allen CIH, Lieberman MD, Martha SMD, William R, Marsha VMD (2004) Adverse Health Effects of Indoor Mould. Aust College of Nutri \& Environ Medicine 23(1):3-8

Da Silva BCM, Auler ME, Ruiz LS (2005) Trichophyton rubrum isolated from AIDS and human immunodeficiency virus-infected patients in São Paulo, Brazil: antifungal susceptibility and extracellular enzyme production. J Chemotherapy 51:21-26

Donohue M, ChungY MML, Ward M, Selgrade MJ, Vesper SJ (2004) Hemolysin Chrysolysin from Penicillium chrysogenum promotes inflammatory response. Int J Hyg Environ Health 208(4):279-85

Eaton KA, Brooks CL, Morgan DR, Krakowka S (1991) Essential role of urease in pathogenesis of gastritis induced by Helicobacter pylori in gnotobiotic piglets. J Infect Immun 59:2470-2475

El-Kady, Moubasher MH (1982) Toxigenicity and toxin of Stachybotrys chartarum isolates from wheat straw samples in Egypt. J Exp Mycol 6:25-31

Ellis D (1994) The Human Opportunistic Mycoses. J Clin Mycol 36(1):166

Eppley RM (1977) Mycotoxins in human and animal health. Pathotox Publishers, Park Forest South, III. V. Rodricks, pp 285-293

Eppley RM, Bailey WJ (1973) 12, 13 Epoxy-A9-trichothecenes as the probable mycotoxins responsible for stachybotryotoxicosis. J Sci 191:758-760

Eppley RM, Highet RJ, Bailey WJ (1980) Structure of satratoxin H, a metabolite of Stachbotrys atra application of proton and carbon - 13 nuclear magnetic resonance. J Org Chem 42:240-243

Faure O, Fricker-Hidalgo H, Lebeau B, Mallaret MR, Ambroise-Thomas P, Grillot R (2000) Eight year surveillance of environmental fungal contamination in hospital operating rooms and haematologic units. J Hosp Infect 50:155-160
Hanzi M, Shimizu M, Hearn VM, Monod M (1993) A study of alkaline protease secreted by different Aspergillus species. J Myco 36:351-356

Harrach B, Bata A, Bajmoczy E, Benko M (1983) Isolation of satratoxins from the bedding straw of a sheep-flock with fatal stachybotryotoxicosis. J Appl Environ Microbiol 45:1419-1422

Hesseltine CW (1985) Global significance of mycotoxins. In: Steyn PS, Vleggaar R (eds) J Mycotox and Phyco- toxins. Elsevier Scientific Publishing Co., Amsterdam, pp 1-18

Hussein HS, Brasel JM (2001) Toxicity, metabolism, and impact of mycotoxins on humans and animals. J Toxicol 167(2):101-134

Ibrahim AS, Mirbod F, Filler SG, Banno Y, Cole GT, Kitajima Y, Edwards JE Jr, Nozawa Y, Ghannoum MA (1995) Evidence implicating phospholipase as a virulence factor of Candida albicans. J Infect Immun 63:1993-1998

International Agency for Research on Cancer (IARC) (1982) The evaluation of the carcinogenic risk of chemicals to humans. Monograph Supplement 4. International Agency for Research on Cancer, Lyon, France

Islam J, Harkema R, Pestka JJ (2006) Satratoxin G from the Black Mold Stachybotrys chartarum Evokes Olfactory Sensory Neuron Loss and Inflammation in the Murine Nose and Brain. J Environ Health Perspect 114:1099-1107

Keller NP, Turner G, Bennett JW (2005) Fungal secondary metabolism - from biochemistry to genomics. J Nat Rev Microbiol 3(12):937-947

Kothary MH, Chase T Jr, MacMillan JD (1984) Correlation of elastase production by some strains of Aspergillus fumigatus with ability to cause pulmonary invasive Aspergillosis in mice. J Infect Immun 43:320-325

Kuiper-Goodman T (2004) Chapter 1. Risk assessment and risk manage- ment of mycotoxins in food. In: Mogan N, Olsen M (eds) Mycotoxins in Food, Detection and Control. CRC Press, New York; Wood head Publishing Limited, Cam- bridge, England, pp 3-31

Kuiper-Goodman T, Ominiski K, Marquardt RR, Malcolm S, McMullen E, Lombaert GAE, Morten T (1993) Estimating human exposure to ochratoxin A in Canada. In: Creppy E, Dirheimer G (eds) Human Ochratoxicosis and Its Pathologies, Montrouge. John Libbey, Eurotech, London, pp 167-74

Kupfahl AM, Cornelia LF, Guido F, Gerhard H, Thomas R, Gernot G, Herbert H (2008) Gliotoxin production by clinical and environmental Aspergillus fumigatus strains. Med Microbiol 298(3-4):319-327

Kwon-Chung KJ, Bennett JE (1992) Mycosis. J Med Mycol, Lea \& Febiger, Philadelphia 31(1):560-593

Mai UEH, Perez-Perez GI, Allen JB, Wahl SM, Blaser MJ, Smith PD (1992) Surface proteins from Helicobacter pylori exhibit chemotactic activity for human leukocytes and are present in gastric mucosa. J Exp Med 175:517-525

Marc Z (2000) Molecular mechanics evaluation of the proposed mechanisms for the degradation of urea by urease. J Biomol Struct Dyn 17(5):787-97

Mobley HL (1996) The role of Helicobacter pylori urease in the pathogenesis of gastritis and peptic ulceration. J Aliment Pharmacol Ther 10:57-64

Monod M, Paris S, Sarfati J, Jaton-Ogay P, Ave P, Latge' JP (1993) Virulence of alkaline protease-deficient mutants of Aspergillus fumigatus. FEMS Microbiol Letters 106:39-46

Monod M, Capoccia S, Lechenne B (2002) Secreted proteases from pathogenic fungi. Int Med J Microbiol 292:405-419

NAS (1993) Pesticides in the Diets of Infants and Children. National Academy Press, Washington, DC, pp 253-258

Nielsen KF (2003) Mycotoxin production by indoor molds. Fungal Genet Biol 39:103-117

Niyo KA, Richard JL, Tiffany LH (1988) Effect of T-2 mycotoxin ingestion on phagocytosis of Aspergillus fumigatus conidia by rabbit alveolar macrophages and on hematologic, serum biochemical, and pathologic changes in rabbits. J Vet Res 49:1766-1773

Pasqualotto AC (2008) Differences in pathogenicity and clinical syndromes due to Aspergillus fumigatus and Aspergillus flavus. J Med Mycol 47(1):1-10

Pasqualotto AC, Denning DW (2006) Post-operative aspergillosis. Clinic Microbiol Infect 12:1060-1076

Paterson RRM, Bridge PD (1994) Biochemical techniques for filamentous fungi. Int J Mycol Instit 1:21

Perdelli F, Cristina ML, Sartini M, Spagnolo AM, Dallera M, Ottria G (2006) Fungal contamination in hospital environments. J Infect Cont Hosp Epidemiol 27:44-47

Pitt JI (1996) What are mycotoxins? Austral. Mycotoxin Newsletter 7(4):1-3 Richard J (1991) Mycotoxins as immunomodulators in animal systems. In: Bray GA, Ryan DH (eds) Mycotoxins, Cancer, and Health. Pennington Center Nutrition Series. Louisiana State University Press, Baton Rouge, LA, pp 197-220 
Rippon JW (1988) The Pathogenic Fungi and the Pathogenic Actinomycetes, 3rd ed., WB Saunders, Philadelphia, 3rd ed. J Med Mycol:797

Ronald MA (2000) Hand book of Microbiological Media, 10th edn. CRC press, Inc, USA, p 137,333,785,279

Salyers A, Witt D (1994) Virulence factors that damage the host. Bacterial pathogenesis: a molecular approach. ASM Press, Washington, D.C, pp 47-62

Sharma RP (1993) Immunotoxicity of mycotoxins. J Dairy Sci 76:892-897

Singh N, Paterson DL (2005) Aspergillus infections in transplant recipients, Review. J Clin Microbiol 18:44-69

Squire RA (1981) Ranking animal carcinogens: a proposed regulatory approach. Sci 214:877-880

Stehr F, Kretschmar M, Kroger C, Hube B, Schafer W (2003) Microbial lipases as virulence factors. Molecular Catalysis, B: Enzymatic 22:347-355

Ullman V, Blasins G (1974) A simple medium for the detection of different lipolytic activity of microorganisms. Zentrabl Bakteriol J Hyg II Abt A 229:264-267

van Egmond HP, Speijers GA (1999) Natural toxins I. Mycotoxins. In: van der Heijden K, Younes M, Fishbone L, Miller S (eds) International Food Safety Handbook, Science, International Regulation, and Control. Marcel Dekker, Inc, New York, Basel, pp 342-355

Vesper SJ, Dearborn DG, Yike I, Sorenson WG, Haugland RA (1999) Hemolysis, toxicity, and randomly amplified polymorphic DNA analysis of Stachybotrys chartarum strains. J Appl Environ Microbiol 65:3175-3181

Vesper SJ, Magnuson S, Dearborn D, Yike I, Haugland RA (2001) Initial characterization of the hemolysin from Stachybotrys chartarum. J Infect Immun 69:912-916

Vonberg RP, Gastmeier P (2006) Nosocomial aspergillosis in outbreak settings. $J$ Hosp Infect 63:246-254

WHO (Environmental Health Criteria) (1986) Principles for evaluating health risks from chemicals during infancy and early childhood; the need for a special approach. IPCS, Geneva

doi:10.1186/2193-1801-2-347

Cite this article as: Aboul-Nasr et al:: Enzymatic and toxigenic ability of opportunistic fungi contaminating intensive care units and operation rooms at Assiut University Hospitals, Egypt. SpringerPlus 2013 2:347.

\section{Submit your manuscript to a SpringerOpen ${ }^{\odot}$ journal and benefit from:}

- Convenient online submission

- Rigorous peer review

- Immediate publication on acceptance

- Open access: articles freely available online

- High visibility within the field

- Retaining the copyright to your article

Submit your next manuscript at $>$ springeropen.com 